British \& Irish Botany 1(4): 335-341, 2019

\title{
Alchemilla sciura (Rosaceae), a new species of Lady's-mantle
}

\author{
Mark Lynes* \\ Doncaster, South Yorkshire, UK
}

*Corresponding author: Mark Lynes: maslyni@gmail.com

This pdf constitutes the Version of Record published on $14^{\text {th }}$ December 2019

\begin{abstract}
The new species Alchemilla sciura (Rosaceae) is described from the Highlands of Scotland. A. sciura belongs to the series Vulgares Buser, subseries subglabrae H.Lindberg. It is known with certainty only from the slopes of The Cairnwell (v.c.90).
\end{abstract}

Keywords: Cairnwell; Red Squirrel; Scotland

\section{Introduction}

Alchemilla is a large and mostly apomictic genus to which in the UK at least relatively little attention has been paid in recent years. No new Alchemilla species has been described since $A$. minima Walters in 1949. My work on the forthcoming BSBI Handbook on Alchemilla has revealed the existence of a small but significant number of undescribed species - several of which have been known about for many years of which this is the first to be formally described. In so doing I hope to stimulate the search for further localities of this and other little-known Scottish taxa.

\section{New taxon}

Alchemilla sciura M. Lynes sp.nov

TYPE. Seasonally flushed mountain slopes of The Cairnwell, Glen Shee (v.c.90), Scotland, 802m altitude NO140776 (holotype (E; Fig.1)); (isotype herb. (M. Lynes)), Vernacular name - Cairnwell Lady's-mantle

\section{Diagnosis}

Resembles Alchemilla glomerulans, differing most obviously in both leaf surfaces being essentially lacking in hairs (other than along the main veins on the underside), and the indumentum of the stem being typically sparse and extending only to the first two or three internodes.

\section{Description}

A perennial, low growing plant, hugging the land. Most of the plant is glabrous or nearly so. Where there are hairs these are adpressed to more or less sub-adpressed, usually dense and rather silky. Basal, rosette, leaves few to more or less numerous and then rather congested on somewhat short petioles, 25 to 60 (90) mm. Upper leaf surface distinctly matt blue-green in colour, almost sea green. The main veins slightly brighter, yellowish, or not; the angle between them $45^{\circ}$ to $60^{\circ}$. The edges of the teeth, or some of them, may yellow in summer and even redden slightly. The 
under-leaf surface is paler and greyer. Blade of well-developed basal leaves 40-45 (65) $\mathrm{mm}$ wide, almost orbicular. Rather flat, yet undulating, the two halves of each lobe twisting in opposite directions, distorted. Difficult to press flat in the herbarium. Basal sinus narrow to overlapping, the basal lobes/lobules often slightly raised. 7(9) lobes, the basal pair often bearing a shorter, narrower lobule. Lobes unequal, usually more or less evenly rounded or truncate. Lobed from barely $1 / 4$ to slightly less than $1 / 3$ of the leaf radius. Sinus between lobes usually distinct, often with a slight notch. Upper leaf surface essentially glabrous, any hairs usually confined to the teeth where they cover the outer edges of the teeth in a silvery-white indumentum. Sometimes the outer edges of one or more lobes or folds also pubescent. The under-leaf surface glabrous save for the main veins which are pubescent the full length or nearly so; densest distally. Teeth 11 to 16 per lobe - 96 to 145 per leaf - unequal and rather widely and distinctly spaced, becoming larger and broader up the lobe. Broad, rather gently and evenly rounded on each side, the leading (inner) edge usually slightly shorter and straighter/more shallowly curved. The apex of each tooth shortly but distinctly pointed, the apex slightly off centre; the trailing (outer) sometimes curving in slightly just before; the larger 1.6 to $2.00 \mathrm{~mm}$ deep (4.4 to $5.4 \%$ of the lamina radius) and 2.1 to $3.9 \mathrm{~mm}$ wide ( 0.4 to $0.8 \times$ as deep as wide). Apical tooth triangular to "minaret"-shaped, usually slightly shorter and narrower than the surrounding teeth and 0.5 to $0.8 \times$ as deep as wide; the teeth either side often the broadest; sometimes only one of them. All teeth end in a dense tuft of whitish hairs. Petioles slender and rounded, the indumentum usually dense and wrapped around them, adpressed to somewhat sub-adpressed. Stipules (Fig. 2) 17$18 \mathrm{~mm}$; adpetiolar cleft 5-6 mm long, curving gradually outwards from the point of fusion, forming a relatively narrow "V"; lobes 4-6 mm wide, obtuse, denticulate; teeth prominent, acute, narrowly to widely spaced, with long projecting hairs; lobes glabrous adaxially, abaxially pubescent proximally, more or less glabrous distally, or hairs may extend proximally along narrow central line; strongly tinged green distally, extending proximally along veins, whitish proximally, may be tinged slightly pinkish in places. Stem long and spreading, procumbent to arcuate, occasionally more or less erect, significantly longer than the basal leaves and 1.5 to $3 x$ as long as the longest petiole. Usually with few branches, concentrated distally and held at a rather wide - approx. $45^{\circ}$ - angle to the stem; sometimes with a lower branch from the $3^{\text {rd }}$ internode. Typically $4(5)$ internodes before the terminal inflorescence branches. The inflorescence nonetheless appears rather narrow. Stem leaves few, the lowest often semi-circular, very shallowly lobed - the lobes barely discernible, the upper more like the basal. All shortly petiolate - the petioles becoming shorter moving up the stem - and with wide basal sinuses of up to c. $80^{\circ}$. Indumentum of the stem usually sparse - sometimes more dense - densest distally, extending to the first two or three internodes. The glomeruli rather small, loose and distinctly flat-topped; irregular. May become much more open when mature. Flowers 2.5 to $3.5 \mathrm{~mm}$ in diameter, yellowish-green in colour. Pedicels 1.2 to $1.9 \mathrm{~mm}$ in length. Hypanthium 1.4 to $1.65 \mathrm{~mm}$ long, 1.04 to $1.31 \mathrm{~mm}$ wide at maturity, obconical. Disc pad in fully developed flowers narrower than aperture. Sepals broadly triangular-ovate, 1.31 to $1.61 \mathrm{~mm}$ long and 0.83 to $1.28 \mathrm{~mm}$ wide. Epicalyx segments narrowly elliptical rather like a narrow, elongated minaret - shorter and narrower than the sepals, 0.94 to $1.02 \mathrm{~mm}$ long and 0.57 to $0.7 \mathrm{~mm}$ wide. All glabrous or nearly so, the sepals sometimes with an occasional hair on the edge. 


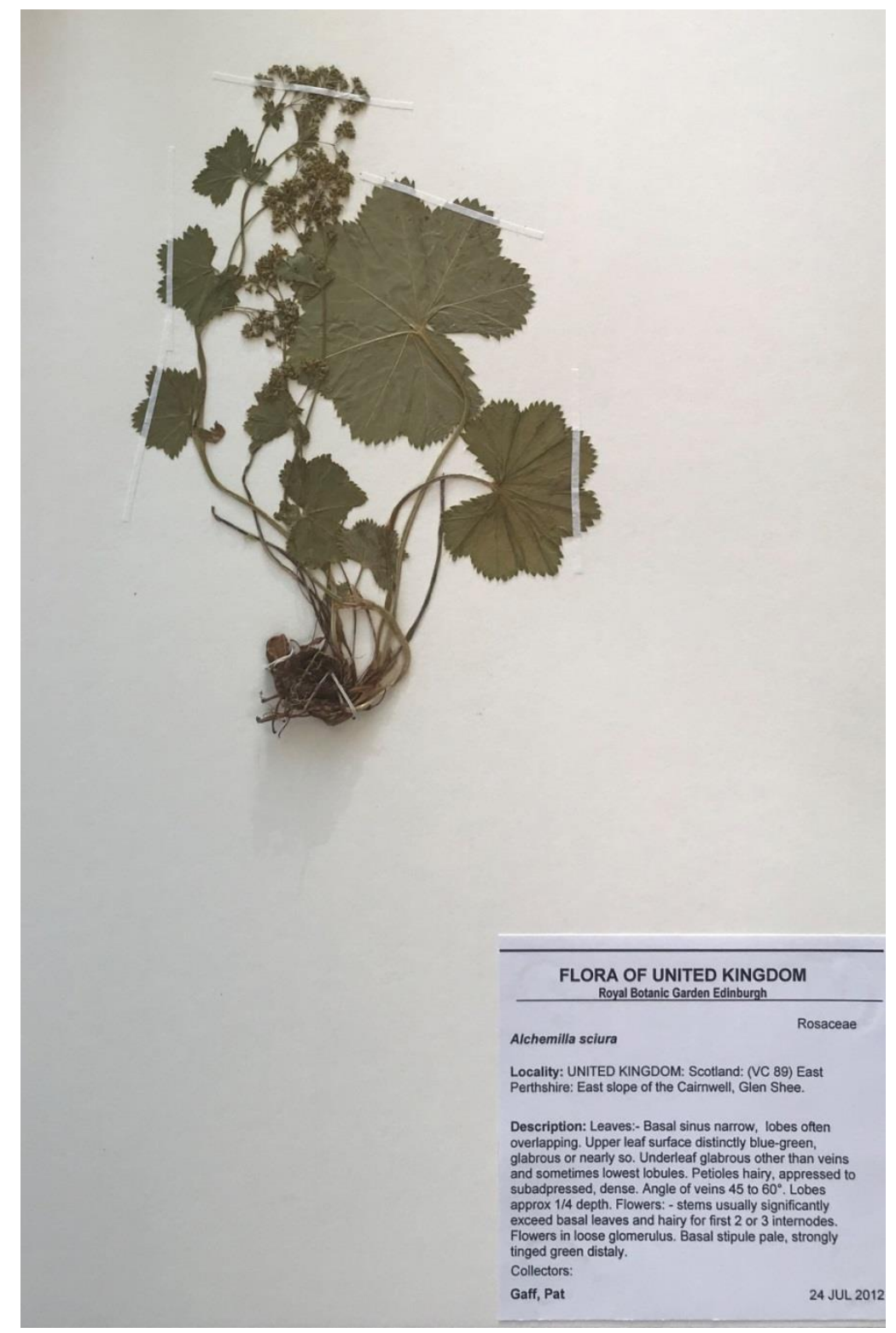

Figure 1. Holotype of A/chemilla sciura

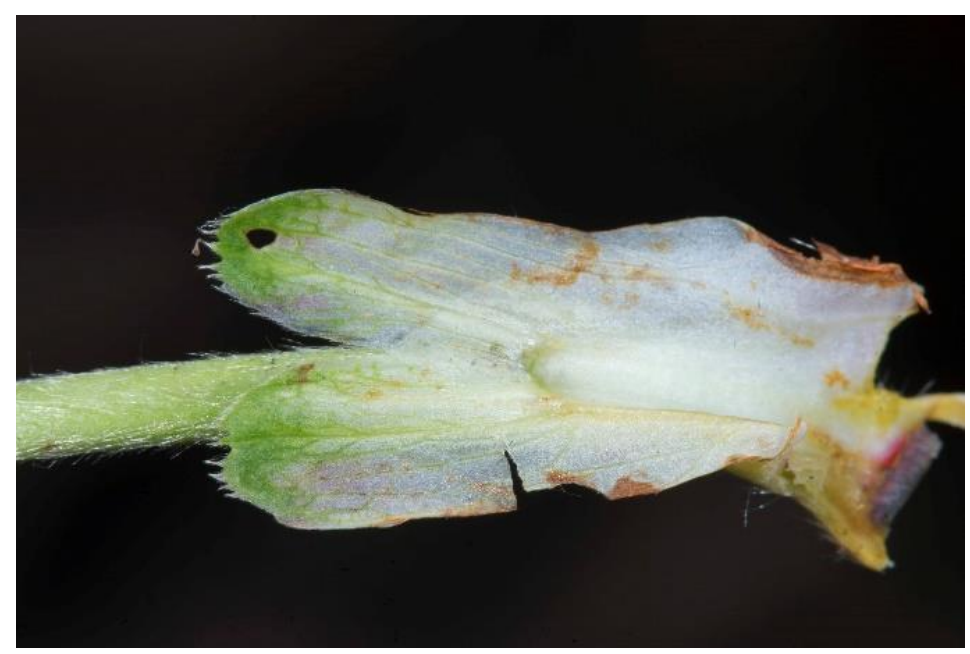

Figure 2. A/chemilla sciura basal leaf stipule 
In the field (Fig. 3) the blue-green colouration of the upper-leaf contrasting with the silvery-white hairs on and emanating from the teeth; the leaves twisted and contorted, with distinctly separate, spiky looking teeth, give the plant a very distinctive appearance. As with many Alchemilla taxa, however, it should not be assumed that leaf colouration will remain constant.

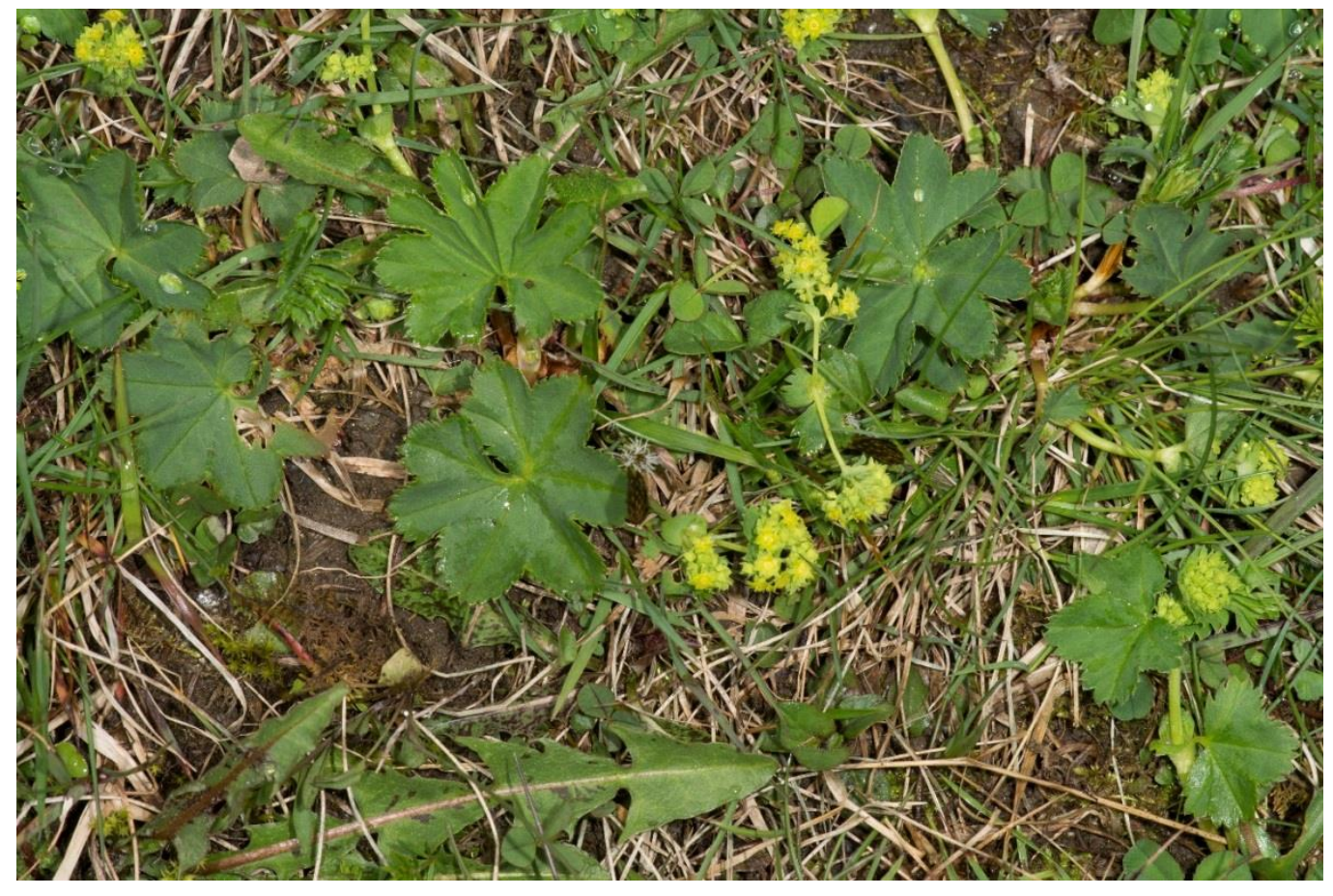

Figure 3. Alchemilla sciura on The Cairnwell

\section{Habitat}

The type locality is the east facing seasonally flushed slopes of The Cairnwell in Glen Shee, Scotland where it grows with other Alchemilla taxa, including $A$. filicaulis Buser, A. glabra Neygenfind and A. glomerulans Buser. So far known from a few highly localised parts of the slopes up to $802 \mathrm{~m}$. Further work needs to be done to understand its precise habitat requirements. In the meantime, it should be looked for elsewhere in similar habitats.

\section{Related species}

This paper has been a long time in gestation, this being largely down to the need to eliminate various similar taxa, some of them little known and really quite obscure.

The closest relative - in the UK at least - appears to be $A$. glomerulans. In its typical form that species differs in a number of ways, the most obvious being the distribution of hairs. In $A$. glomerulans both leaf surfaces are usually covered in adpressed hairs and the stem is typically hairy all the way up to the terminal inflorescence branches at least, occasionally extending into the hypanthia themselves. In recent years, however, a small number of plants otherwise determinable as this species have been found which are essentially glabrescent. Other than with respect to the indumentum all specimens so far examined have otherwise appeared to accord with glomerulans and have appeared quite different from $A$. sciura. More work needs to be done to understand just what these glabrescent plants are. 
A. glomerulans also differs in its typically yellower appearance and in the shape and consistency of the glomeruli, which are more rounded and compact. The leaf teeth of $A$. glomerulans are also quite different not only numerically but also in size, shape and distribution, being much more ordered and closer together. Finally, unlike glomerulans and all currently described British species, $A$. sciura is highly polyploid (Gerold Hügin pers. comm).

The little known and poorly understood $A$. glomerulans $f$. glabrior C.G. Westerlund was an early candidate for consideration. However, within the last few years I have been fortunate in acquiring several herbarium specimens attributed to this taxon collected by the late Erik Evers. Examination of these has shown them to be much closer to $A$. glomerulans than to $A$. sciura, differing in several respects including again the toothing and the indumentum. A plant found by the late Stefan Ericsson and me in Norway in 2014 but not collected, now seems likely to have been this taxon also, however unfortunately it was not recognised as such at the time. It may be that forma glabrior is also worthy of specific recognition.

Westerlund also described a further variety of glomerulans, forma descalyx. Whilst I have not yet been able to locate any specimens of this form, Westerlund's description leaves me in no doubt it is not the same taxon as $A$. sciura as it is far hairier than $A$. glomerulans s.s.

The ostensibly very similar, yet localised Swedish endemic $A$. taernaensis $\mathrm{Hyl}$. ex S. Ericsson \& S. Hellqvist (Fig. 4) must also be discounted. In this I am very fortunate in having been shown the plant by Stefan Ericsson - one of its describers in Sweden in 2012. I am also in possession of a number of herbarium specimens determined by Ericsson, including one of the isotypes. However, it was felt essential also to have the species in cultivation in order to be able to critically examine the full suite of features. Unfortunately, I had neglected to collect living material back in 2012 and it was not until 2018 that a specific collecting trip was made for this purpose. $A$. taernaensis differs from $A$. sciura in a variety of ways, most obviously again in the toothing. The teeth of $A$. taernaensis are really quite remarkable. They are much larger and broader and there are more of them. The indumentum of $A$. taernaensis is also different, being even more restricted than is typically the case with sciura and lacking the distinctive tufted tooth tips which give the species its name. It is also necessary here to mention the shiny appearance of the upper leaf surface mentioned by Ericsson and Hellqvist (1993) when describing A. taernaensis. The two authors placed some significance on this feature when describing the species. However, Ericsson made no mention of it when we found it near its type locality in 2012 - not least when describing the plant in Figure 3 as a classic plant and insisting it be collected for my personal herbarium. This feature was not apparent to me in any of the several hundred plants seen in 2012, it is not apparent in any photographs taken at the time, nor in plants now in cultivation. It may be this was a peculiar feature of the plants at the type locality. However, when on visiting the supermarket concerned, we found the site of the type collection had been turned into part of the car park and the plants destroyed. 


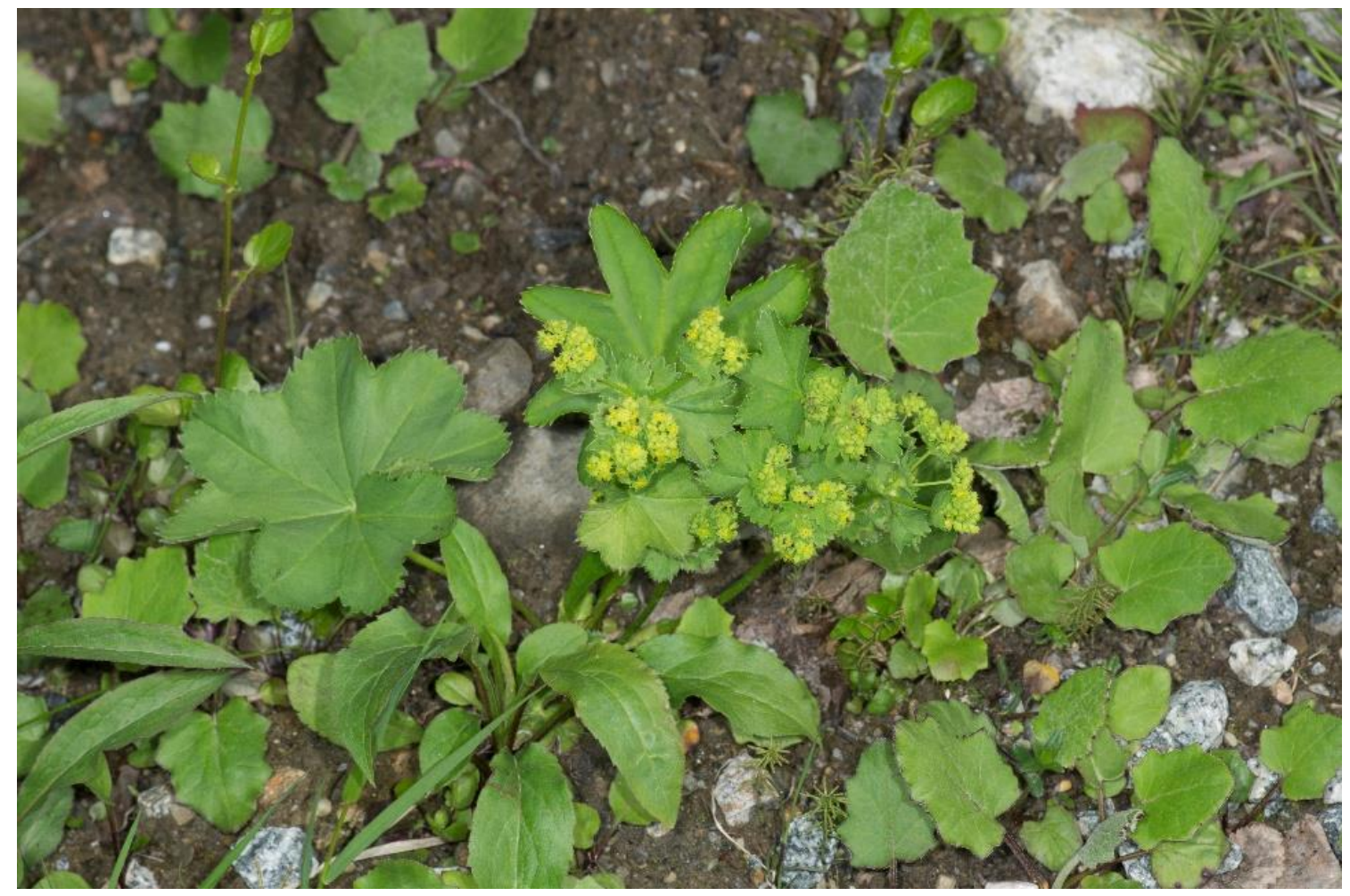

Figure 4. Alchemilla taernaensis near Tärnaby, Sweden

\section{Etymology}

Named after the distinctive tufted tips to the teeth which reminded Dr Margaret Bradshaw of the ear tufts of a Red Squirrel Sciurus vulgaris when shown specimens of the new species.

\section{Conservation status}

A. sciura is classified as IUCN Threat Category "Endangered" (IUCN 2001) due to the small known population size. There appears to be no immediate threat to its survival, albeit the known populations are small and potentially vulnerable to over collecting.

\section{Acknowledgements}

I thank Barbara Hogarth for alerting me to the presence of a rich assemblage of Alchemilla on the slopes of The Cairnwell, of which this plant is part. Sven Hellqvist and Jim McIntosh arranged access to various specimens. Hans Rydberg kindly sent me a copy of the Westerlund paper. Leszek Mackiewicz and Alexis Fitzgerald made a special trip to collect living material of $A$. taernaensis. The late Gerold Hügin arranged for cytometric analysis. The late Stefan Ericsson showed me $A$. taernaensis in the field and gifted me one of the isotypes. Finally, Jeremy Roberts commented on an earlier draft of this paper, which has been greatly improved as a consequence.

\section{References}

Ericsson, S. \& Hellqvist, S. 1989: Nyckel till daggkåpor, Alchemilla, i Västerbottens län. Natur i Norr 8: 21-56

Ericsson, S. \& Hellqvist, S. 1993: Alchemilla taernaensls, en ny daggkåpa från Lycksele lappmark. Svensk Bot. Tidskr.87: 5-14. 
IUCN. 2001. IUCN Red list categories and criteria. Version 3.1. Gland: IUCN. Walters, S.M. (1949). Alchemilla vulgaris L. in Britain. Watsonia 1: 6-18.

WesterIund, C.G. 1907: Studier öfver de svenska formerna af Alchemilla vulgaris L. Redog. Allm. Lärov. Norr.-Söderköping 1906-07. 31 s.

Copyright retained by author(s). Published by BSBI under the terms of the Creative Commons Attribution 4.0 International Public License.

ISSN: $2632-4970$

https://doi.org/10.33928/bib.2019.01.335 